\title{
Investigation of the Basic Properties of Ceramic Proppants in Raw State Obtained by the Method of Mechanical Granulation
}

\author{
D. ZarzyckA*, P. Wisniewski, M. Malek, J. Szymanska and J. Mizera \\ Faculty of Materials Science and Engineering, Warsaw University of Technology, \\ Wołoska 141, 02-507 Warsaw, Poland
}

\begin{abstract}
The investigation of fabricated ceramic materials, which can be used as proppants, is presented. Proppants are ceramic materials applied in hydraulic fracturing during extraction of shale gas. Solid slurry pumped with liquid into the deposit causes destruction of the rock structure. The role of proppants is to avoid closing of formed pores and as result enable gas migration from the deposit. Due to processing requirements and conditions in formations (high pressure and temperature), proppants should be characterized by proper physico-mechanical properties. The aim of this work was to elaborate the preparation method of ceramic materials, which can be used as proppants. In this paper results of properties studies of obtained proppants are presented. The influence of raw materials composition, especially the type of applied binder, was examined. Two types of green proppants obtained by the method of mechanical granulation without binder and with poly(vinyl alcohol) in amount of 5 wt $\%$ with respect to the powder were used. The properties: bulk density, roundness and sphericity coefficient, grain size and also structure and morphology of proppants was determined by the method of scanning electron microscopy with energy dispersive spectroscopy. The results indicate that composition of raw materials and type of binder have an important influence on the properties of obtained proppants in green state.
\end{abstract}

DOI: 10.12693/APhysPolA.129.552

PACS/topics: 81.05.Je

\section{Introduction}

The most important component of the fracturing fluid used in the extraction of hydrocarbons in unconventional reservoirs are proppants $[1,2]$. Their task is to prevent the closure of and maintain microcracks in the rock previously manufactured by them $[3,4]$. As a result of such action the free flow of hydrocarbons trapped in rock creations, flows through the spaces between the grains and rises to the surface. After completion of the fracturing process and the ceasing of pumping the fracturing fluid into the wellbore, remaining in the deposit is solely proppant. Its quality and distribution [5] determines the efficiency of the flow of a resource $[4,6]$. Therefore, the choice of material for filling the role of the particular physical and mechanical proppant requires properties of: a suitable specific gravity, high crush strength, a suitable particle size, uniformity, sphericity and smoothness [7].

It is known that strict prevailing downhole pressure and temperature conditions of the formation, as well as the fracturing process uses high pressure of $60 \mathrm{mPa}$ [8]. Crumbling proppants is an undesirable feature [9], since small particles clog channels causing light impeding or preventing the flow of the hydrocarbons. Homogeneity of the particles is important, as the obtained medium (gas, liquid) flows more easily between particles of the same size [10]. Roundness and sphericity of proppants

*corresponding author; e-mail: d.zarzycka@inmat.pw.edu.pl has a direct influence on the arrangement of the material in rock crevices and affects the efficiency of extraction of hydrocarbons [5]. The more grain size is less varied and are spherical, the more optimum is the positioning in the gap and better gas flow [5]. Gravity is very important because of the need to suspend the proppants in hydraulic fracturing fluid.

The ideal proppant should have the following characteristics, providing a good release of gas from the field:

- have adequate compressive strength of the order of 15,000 to 20,000 psi, i.e. $\max \approx 139 \mathrm{mPa}$;

- have a uniform particle size distribution;

- have a perfect sphericity and roundness;

- have an appropriate material density, preferably about $2 \mathrm{~g} / \mathrm{cm}^{3}$;

- be chemically inert to the fracturing fluid containing various chemical compounds [3].

The history dates back to the early 50 s of the 20th century, when naturally occurring sand was used as proppants $[8,11]$ with a large percentage of $\mathrm{SiO}_{2}$. It concluded that this material despite the attractive price exploited a number of undesirable properties such as poor mechanical strength, different grain size and irregular shape [12], thus favoring the close-packing in the fissures, and consequently preventing gas migration. It was further found that the sand can be used only for the deposits easier to 
operate at low pressure $[8,12]$. The next step in the development of proppants was the appearance of ceramic proppants, obtained mainly from calcined bauxite and kaolin, and mixtures of magnesium silicate [8]. These obtained proppants in comparison to sand are characterized by higher strength and a more spherical shape. A disadvantage however was higher specific gravity which created problems during their transport through the liquid into the wellbore. Further exploration consisted of coating by resins using the above mentioned proppants (sand and ceramic) $[8,13]$. Through this process the strength and sphericity were improved [8]. Attempts have also been made using proppant nutshells $[8,13]$ and metallic particles [8]. In both cases, problems resulted from using the specific gravity size (too small or too large). In addition, shells proved to be too brittle, metallic proppants too expensive and not very resistant to acidic environment.

As a result, the greatest hopes are in ceramic proppants whose properties can be shaped and adapted to present needs [14]. Ceramic proppants [15, 16] with appropriate parameters: size, durability, roundness and sphericity, resistant to the conditions prevailing in the deposit may increase the stimulation of the shaft as much as $30 \%$. Large-scale theoretical modeling and practical case experience suggest that the ceramic bodies demonstrate compelling benefits relative to sand and may be used in the majority of wells, notably deep wells where the sand's crush strength is inadequate.

With this in mind and the need to intensify work on the exploitation of Polish shale gas deposits, the work on the preparation of ceramic proppants based on domestic raw materials was undertaken. This publication presents preliminary preparative work and preliminary studies of some parameters of green proppants. To test the correct performance of final product in one of the batches there was used a binder. Suitable binder added in a small amount (less than $1 \%$ relative to the solid phase) may molders [17].

\section{Materials and methods}

\subsection{Proppants}

Ceramic proppants were produced by mechanical granulation mixtures of natural minerals, composed of clay $(40 \mu \mathrm{m})$, kaolin $(40 \mu \mathrm{m})$ and bauxite $(20 \mu \mathrm{m})$ with a content correspondently 40, 40, $20 \mathrm{wt} \%$.

Two types of proppants marked S1 and S2 were prepared.

- S1 proppants were prepared without the addition of the binder.

- S2 proppants (with binder) — with $20 \%$ solution of poly(vinyl alcohol) PVA whose quantity in relation to the powder was $5 \%$ by weight.

The maximum stirring speed was $3500 \mathrm{rpm}$, the time of preparation of proppants amounted to $5 \mathrm{~min}$.
The study determined the raw material bulk density, particle size as well as roundness and the sphericity coefficient $[7,18]$. The morphology was determined by scanning electron microscopy (SEM) with energy dispersive spectroscopy (EDS) analysis.

\subsection{Roundness and sphericity}

The roundness and sphericity test of proppants grains was described in ISO 13503-2:2006 [18]. Assessment can be done visually by comparing the shape of the grains using the diagram Krumbein/Sloss [19]. This shows the visual evaluation method of the roundness (angularity) and sphericity of proppants grains. Discussed was the need to select at least 20 different grains of a single layer of material under test. Observations were carried out using an optical microscope type Motic SMZ-168 equipped with a Nicon DS-FI 2 camera. American Petroleum Institute standards recommend sphericity and roundness of 0.6 or larger (API $\geq 0.6)$ [7].

\subsection{Bulk density}

The bulk density of proppants was determined by gravimetric method, determining the weight of material of a known volume [18]. This parameter is important for quantifying the mass of proppants needed to fill the gap or during transport and storage of the material.

\subsection{The particle size and morphology}

The size and shape of the particles was determined by SEM, their structure and morphology by SEM with EDS using Hitachi TM 1000 electron microscope.

\section{Results and discussion}

Using an optical microscope an uneven distribution of proppant particles (marked S1 crude obtained without the binder), were found. The material includes both large particles with a diameter of about $500 \mu \mathrm{m}$, and very fine. The visual assessment of the sphericity of the proppants $\mathrm{S} 1$ is impossible (Fig. 1a). a)

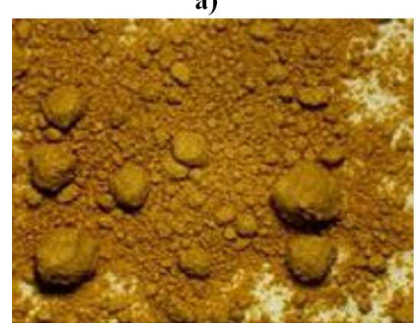

b)

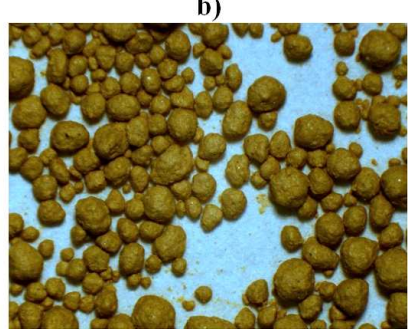

Fig. 1. Shapes and size in optical microscope of (a) proppants $\mathrm{S} 1$, (b) proppants $\mathrm{S} 2$.

Proppants marked S2 obtained by using PVA as a binder is characterized by a homogeneous particle size distribution and sphericity (Fig. 1b), with, according to visual evaluation, a particle diameter of from $500 \mathrm{\mu m}$ 
to $1 \mathrm{~mm}$. SEM micrographs of raw proppants samples S1 and S2 (Figs. 2 and 3) show the differences in both materials in terms of their grain size, shape, and surface morphology. Proppants S1 is a heterogeneous material and particle size distribution is very large from about $50 \mu \mathrm{m}$ to over $500 \mu \mathrm{m}$, the non-uniform shape can be seen (Fig. 2a). Most green S2 proppants (Fig. 3a) have a size of $500 \mu \mathrm{m}$ but there are also grains twice the size. S2 grains are more similar in shape to a ball. Also, the surface morphology of the samples S1 and S2 is different (Fig. 2b and 3b). S1 proppants surface seems more rough than S2 proppants. On the surface of the sample material S1 there are noticeable micropores.
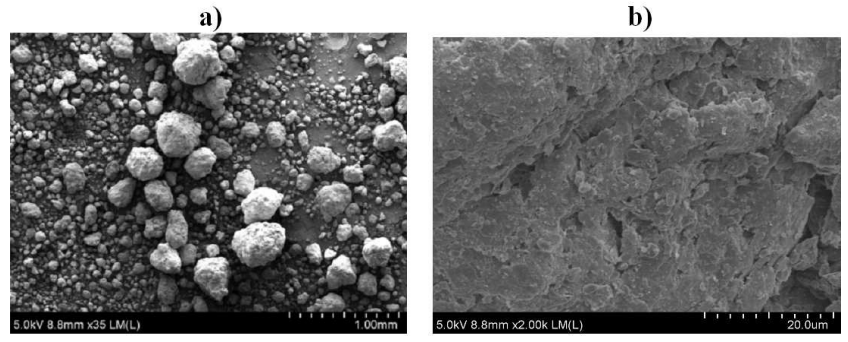

Fig. 2. SEM micrographs of proppants S1 a)

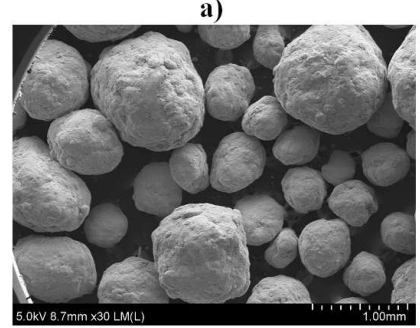

b)

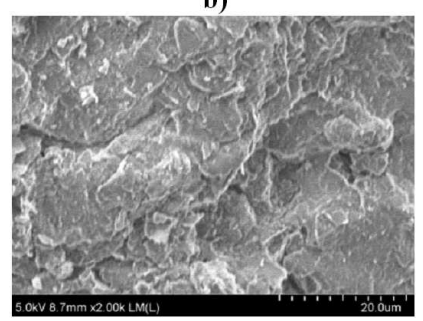

Fig. 3. SEM micrographs of proppants S2.

Energy dispersive X-ray spectroscopy analysis of green proppants S1 and S2 show a similar content of elements, amongst which dominate aluminium, silicon and oxygen. Also detected were trace volumes of potassium, calcium, iron and titanium.

The results of analysis of roundness (angularity) and sphericity in green state are summarized in Table I.

TABLE I

Roundness and sphericity coefficients for proppants in raw state.

\begin{tabular}{c|c|c}
\hline \hline Proppant & $\begin{array}{c}\text { Roundness } \\
\text { coefficient }\end{array}$ & $\begin{array}{c}\text { Sphericity } \\
\text { coefficient }\end{array}$ \\
\hline S1 & 0.8 & 0.6 \\
S2 & 0.9 & 0.7
\end{tabular}

Favorable parameters characterize roundness and sphericity of proppant series S2.

Differences in the sphericity of green proppants S1 and $\mathrm{S} 2$ can be seen in Fig. 4, showing the shapes of grain using a 1.04 MicroMeter program.

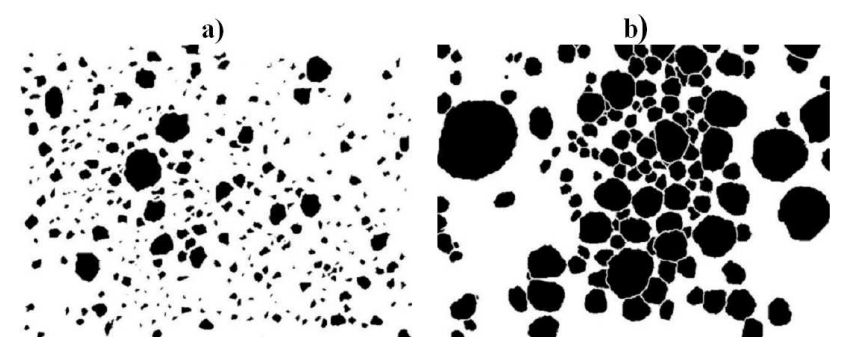

Fig. 4. Outlined proppants particles: pants $\mathrm{S} 1$, (b) proppants $\mathrm{S} 2$.

(a) prop-

\section{Conclusions}

The research found that, using as raw material components (kaolin, clay, bauxite), and poly(vinyl alcohol) used as a binder, filling material (S2), can be obtained by granulation, which is characterized by a favorable raw particle size distribution, a high ratio of sphericity and smooth surface. Both materials meet the standards of roundness and sphericity. But at the same time, it was found that the absence of a binder makes it impossible to obtain a material having desired grain size property. S1 material turned out subsequently to have less desirable properties. Bulk density of green materials, S1 and S2 housed $1-3 \mathrm{~g} / \mathrm{cm}^{3}$ within the desired limits.

\section{Acknowledgments}

Studies of lightweight ceramic proppants were realized within the framework of BLUE GAS Programme financed from The National Centre for Research and Development. Project title: "Optimizing the lightweight high strength and low specific gravity ceramic proppants production technology maximally using naturally occurring Polish raw materials and fly ash", No. BG1/BALTICPROPP/13.

\section{References}

[1] A. Reinicke, E. Rybacki, S. Stanchits, E. Huenges, G. Dresen, Chem. Erde 70, 107 (2010).

[2] D.R. Watson, V.G. Carithers, L. Rock, L.T. McDaniel, US Patent 4555493, 1985.

[3] D. Mader, Developments in Petroleum Science, Vol. 26, Elsevier, 1989.

[4] M.J. Economides, D.A. Hill, C. Ehlig-Economides, Petroleum Production Systems, Prentice Hall, 1993.

[5] M. Kulkarni, O.O. Ochoa, Compos. Sci. Technol. 72, 879 (2012).

[6] M.J. Economides, K.G. Nolte, Reservoir Stimulation, Wiley (2000).

[7] API, Recommended practices for testing for highstirring proppants in hydraulic fracturing operations, API RP 60, 1995.

[8] M. O'Driscoll, in: Proc. Industrial Minerals Research, 19th Bauxite and Alumina Conf., Miami 2013, p. 45 . 
[9] J.D. Weaver, P.D. Nguyen, M.A. Parker, D. van Batenburg, in: Proc. SPE European Formation Damage Conf., Red Hook, New York 2005, p. 94666.

[10] I. Treviranus, "Importance of size and shape for proppants quality", ASTM D18.26 Jacksonville, FL 2013.

[11] W.C. Krumbein, L.L. Sloss, in: Stratigraphy and sedimentation, 2nd Ed., Freeman and Co., San Francisco 1963 , p. 660.

[12] E. Breval, J.S. Jennings, S. Komarneni, N.H. Macmillan, E.P. Lunghoffer, J. Mater. Sci. 22, 2124 (1987).

[13] A. Gaurav, E.K. Dao, K.K. Mohanty, J. Petrol. Sci. Eng. 92, 82 (2012).

[14] A.R. Rickards, H.R. Brannon, W.D. Wood, C.J. Stephenson, SPE Prod. Oper. 21, 212 (2006).
[15] R.S. Aboud, R.C.B. Melo, in: Lat. Am. and Carib. Petrol. Eng. Conf., SPE, Buenos Aires 2007, p. SPE 107184.

[16] H.D. Brannon, M.R. Malone, A.R. Rickards, W.D. Wood, J.R. Edgeman, J.L. Bryant, in: Proc Annual Techn. Conf. and Exhib., Houston (USA), 2004, p. SPE 90698.

[17] A.G. King, Ceramic Technology and Processing, Noyes Publ., Norwich (NY) 2002.

[18] ISO 13503-2, Measurement of Properties of Proppants used in Hydraulic Fracturing and Gravel-Packing Operations, 2006.

[19] W.C. Krumbein, L.L. Sloss, Stratigraphy and Sedimentation, Freeman, California 1955. 